\title{
MORPHOLOGY AND FRACTAL CHARACTERIZATION OF MULTISCALE PORE STRUCTURES FOR ORGANIC-RICH LACUSTRINE SHALE RESERVOIRS
}

\author{
YANG WANG, ${ }^{*, \dagger}$, CAIFANG WU, ${ }^{*, \dagger}$ YANMING ZHU, ${ }^{*, \dagger}$ \\ SHANGBIN CHEN $, *, \dagger$ SHIMIN LIU ${ }^{\ddagger}$ and RUI ZHANG ${ }^{\ddagger}, \S$ \\ *Key Laboratory of Coalbed Methane Resources and \\ Reservoir Formation Process, Ministry of Education \\ China University of Mining and Technology \\ Xuzhou, Jiangsu 221008, P. R. China \\ †School of Resources and Earth Science \\ China University of Mining and Technology \\ Xuzhou, Jiangsu 221116, P. R. China \\ ${ }^{\ddagger}$ Department of Energy and Mineral Engineering \\ $\mathrm{G}^{3}$ Center and Energy Institute \\ The Pennsylvania State University \\ University Park, PA 16802, USA \\ $\S$ Biology and Soft Matter Division \\ Oak Ridge National Laboratory \\ Oak Ridge, TN 37831, USA \\ 『wangycumt@163.com
}

Received December 5, 2017

Accepted January 8, 2018

Published February 20, 2018

\begin{abstract}
Lacustrine shale gas has received considerable attention and has been playing an important role in unconventional natural gas production in China. In this study, multiple techniques, including
\end{abstract}

\footnotetext{
"Corresponding author.

This is an Open Access article published by World Scientific Publishing Company. It is distributed under the terms of the Creative Commons Attribution 4.0 (CC-BY) License. Further distribution of this work is permitted, provided the original work is properly cited.
} 
Y. Wang et al.

total organic carbon (TOC) analysis, X-ray diffraction (XRD) analysis, field emission scanning electron microscopy (FE-SEM), helium pycnometry and low-pressure $\mathrm{N}_{2}$ adsorption have been applied to characterize the pore structure of lacustrine shale of Upper Triassic Yanchang Formation from the Ordos Basin. The results show that organic matter (OM) pores are the most important type dominating the pore system, while interparticle (interP) pores, intraparticle (intraP) and microfractures are also usually observed between or within different minerals. The shapes of OM pores are less complex compared with the other two pore types based on the Image-Pro Plus software analysis. In addition, the specific surface area ranges from $2.76 \mathrm{~m}^{2} / \mathrm{g}$ to $10.26 \mathrm{~m}^{2} / \mathrm{g}$ and the pore volume varies between $0.52 \mathrm{~m}^{3} / 100 \mathrm{~g}$ and $1.31 \mathrm{~m}^{3} / 100 \mathrm{~g}$. Two fractal dimensions $D_{1}$ and $D_{2}$ were calculated using Frenkel-Halsey-Hill (FHH) method, with $D_{1}$ varying between 2.510 and 2.632, and $D_{2}$ varying between 2.617 and 2.814. Further investigation indicates that the fractal dimensions exhibit positive correlations with TOC contents, whereas there is no definite relationship observed between fractal dimensions and clay minerals. Meanwhile, the fractal dimensions increase with the increase in specific surface area, and is negatively correlated with the pore size.

Keywords: Lacustrine Shale Gas; Pore Structure; Fractal Dimension; Yanchang Formation; Ordos Basin.

\section{INTRODUCTION}

The growing environmental problem and contradiction between energy supply and energy demand have led to much interest in shale gas over the past few years. Following the shale gas revolution in North America and the rapid development of advanced techniques of horizontal drilling and hydraulic fracturing, the commercial exploitation of shale gas reservoirs has increased in China in the past few years. $\frac{1+3}{1-}$ As an unconventional reservoir, shales are generally characterized by low porosity and low permeability matrix with extensive heterogeneous nanoscale pores. ${ }^{4}$. 7 According to the classification of the International Union of Pure and Applied Chemistry (IUPAC), pores developed in shales can be classified into three categories: micropore $(<2 \mathrm{~nm})$, mesopore $(2-50 \mathrm{~nm})$ and macropore $(>50 \mathrm{~nm}) .[$ The pore structure of shales play an important role in the gas occurrence state, gas storage capacity and gas flow behavior $\frac{499}{14}$ Thus, quantitatively characterizing the nanoscale pore structure is essential for evaluating the quality of the shale reservoir.

The pore structure system in shale reservoirs is heterogeneous, with variable pore diameter, shape, connectivity and spatial distribution, which is difficult to elucidate pore structures 15 Multiple techniques have been used to characterize the pore structure mainly including direct imaging and indirect fluid penetration methods ${ }^{4[18}$ Direct imaging methods, including transmission electron microscopy (TEM), field emission scanning electron microscopy (FE-SEM) and atomic force microscopy (AFM), can directly obtain high-resolution images of the pore structures. These imaging techniques are used to qualitatively characterize pore morphology, pore size and connectivity $\frac{19 ; 20}{1}$ Indirect fluid penetration methods, including nuclear magnetic resonance (NMR), helium pycnometry, lowpressure $\mathrm{N}_{2} / \mathrm{CO}_{2}$ adsorption and high-pressure mercury injection and mercury intrusion capillary porosimetry (MICP), can be widely used to quantitatively measure the pore structures (specific surface area, pore volume and pore size distribution) $\frac{4121 \sqrt{23}}{}$ Among these, low-pressure $\mathrm{N}_{2}$ adsorption and desorption experiments are considered as standard methods for nanoscale pore analysis.

Fractal theory can be used to characterize the heterogeneity and complexity of porous materials and has been proven to be an effective method to study the irregularity and surface roughness of shale pores. 23 A large fractal dimension indicates a more complicated pore structure and more rough pore surface. Several pore characterization techniques, including small angle X-ray scattering (SAXS), MICP, FE-SEM and lowpressure $\mathrm{N}_{2}$ adsorption can be used to calculate fractal dimension $\sqrt[30]{35}$ Note that low-pressure $\mathrm{N}_{2}$ adsorption has been considered as the simplest and most cost-effective method to analyze the fractal dimension. $36+38$ In addition, high-resolution 
FE-SEM images can be used to characterize intuitive two-dimensional fractal characteristics of shale pore structures. Combining these two methods provides a thorough analysis of pore structure heterogeneity and complexity.

Organic-rich shales are widely distributed throughout China in marine, transitional marine and lacustrine depositional environments! $\frac{10}{10}$ Compared with the significant success that marine shale gas development has achieved in China,, 39 less attention has been paid to lacustrine shale gas and relatively few studies have been conducted on the fractal characterization of lacustrine shales. Therefore, the purpose of this paper is to give a more specific study of nanoscale pore system of the lacustrine shale reservoir. Fractal analyses on Upper Triassic Yanchang Formation from the Ordos Basin in central China have been carried out. Fractal dimensions of the pore structures were calculated using the Frenkele-Halseye-Hill (FHH) method. Then the relationships between TOC, mineral content, pore structure parameters and fractal dimensions were analyzed and discussed. The results will add the technical merit for the shale gas in place of estimation and reservoir evaluation for lacustrine shales.

\section{SAMPLES AND METHODS}

\subsection{Sample Collection and Preparation}

The study area of this investigation is located in the Ordos Basin, which is located in the central part of the North China Plate (Fig. 1). Ordos Basin is the second largest sedimentary basin in China and famous for enormous natural gas resources.40 The Ordos Basin was a Paleozoic intracratonic sag basin, which has undergone complex tectogenesis. The lacustrine shale from Chang-7 of Yanchang Formation was formed in a continental sedimentary environment in the Triassic (Fig. 1). For a systematic study of pore structures of lacustrine shale, fresh shale samples from DT-1 well and short-hole drillings were collected due to their variability of TOC contents. Each sample was cut into several parts for analyzing the mineralogical composition, organic petrography and pore structures.

\subsection{Geochemical and Mineralogical Parameters}

Prior to the pore structure characterization experiments, geochemical parameters and mineral

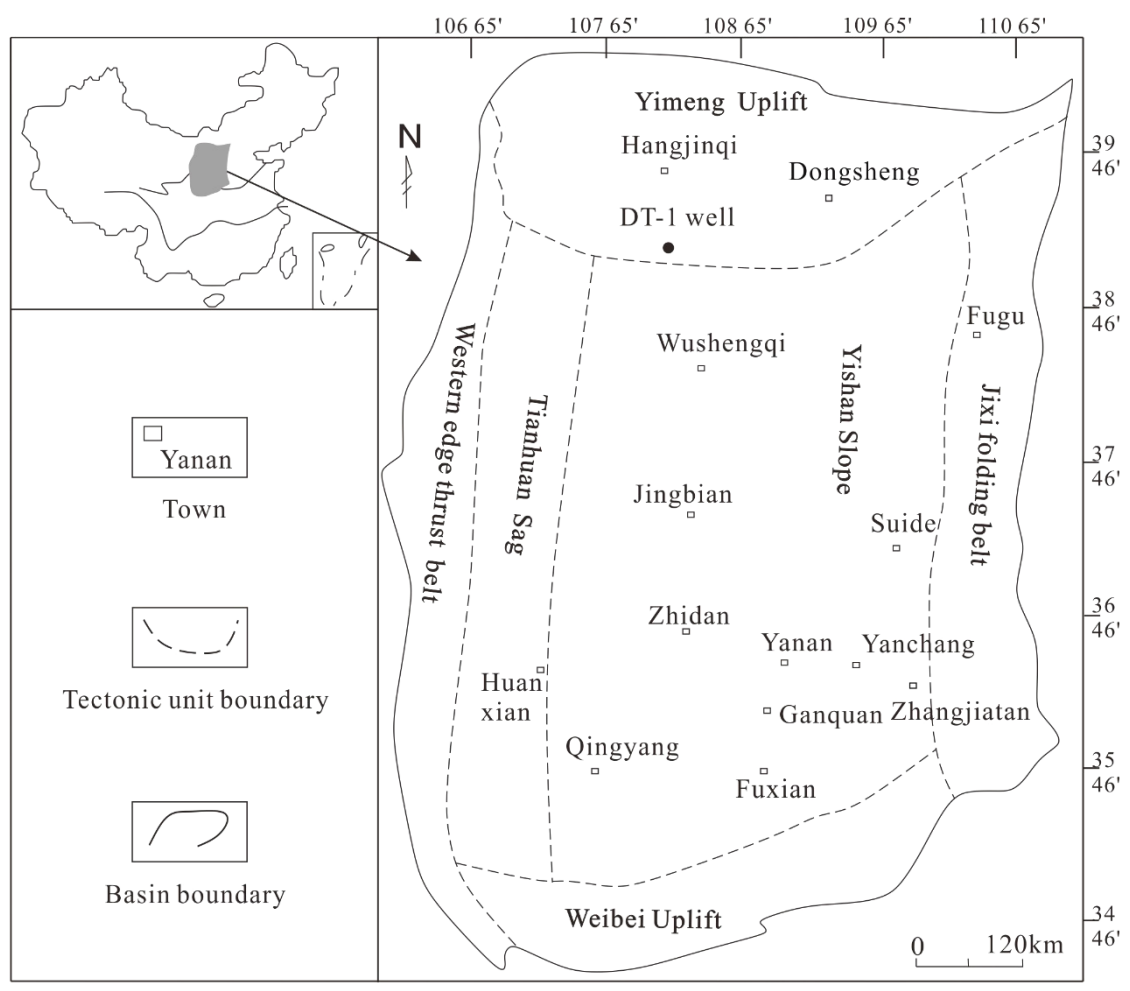

Fig. 1 The location of the study area and the tectonic zones of the Ordos Basin. 
composition of all collected shale samples were measured. The analysis of total organic carbon (TOC) was performed using LECO CS-230 carbon and sulfur analyzer. Mineral composition was derived from RIGAKU D/Max-3B type X-ray diffractometer. All analyses were carried out at the Experimental Research Center of East China Branch, SINOPEC.

\subsection{FE-SEM Characterization}

The FE-SEM observations were performed using a Quanta 200F instrument at the China University of Petroleum, Beijing Campus (CUP). The FE-SEM images can provide a spatial resolution of $1.2 \mathrm{~nm}$ which is sufficient for characterization of nanoscale pore morphology. Prior to the experiment, the measured samples were prepolished with argon ion mill and then gold was coated onto the artifact-free surface for observation. Samples were oven dried at $65^{\circ} \mathrm{C}$ for $12 \mathrm{~h}$. The experiment was carried out at a constant temperature of $24^{\circ} \mathrm{C}$ and $35 \%$ humidity.

\subsection{Porosity Using Helium Pycnometry}

The total porosity of shale samples was determined at the Experimental Research Center of East China Branch, SINOPEC, using a technique based on Boyle's Law, by measuring the grain volume under ambient conditions and bulk volume by Archimedes' principle with helium pycnometry. Samples were oven dried at $115^{\circ} \mathrm{C}$ to a constant weight $( \pm 1 \mathrm{mg})$. Porosity was calculated from the difference between bulk volume and grain volume.

\subsection{Low-Pressure $\mathrm{N}_{2}$ Adsorption Characterization}

The low-pressure $\mathrm{N}_{2}$ adsorptions were measured using a Quantachrome Autosorb-1 apparatus in China University of Mining and Technology. Between 3 to $5 \mathrm{~g}$ of 60 mesh samples were outgassed and dried at $\sim 110^{\circ} \mathrm{C}$ for approximately 14 hours prior to the $\mathrm{N}_{2}$ adsorption experiments. The $\mathrm{N}_{2}$ adsorption isotherms were obtained under the relative pressure $\left(P / P_{0}\right)$ ranges from 0.009 to 0.995 at the temperature of liquid nitrogen $(77 \mathrm{~K}$ at $101.3 \mathrm{kPa}$ ). The pore structure parameters (including surface area, pore volume and pore diameter) were calculated using the multi-point BrunauerEmmett-Teller (BET) model and Barrett--JoynerHalenda (BJH) model from the adsorption branch of the isotherm. .513 A detailed description of these theories can be found in Gregg and Sing!

\subsection{Fractal Characterization}

Fractal geometry has been widely used to describe the porous structure and surface irregularity of porous solid which directly influences the sorption behaviors. 2814244 Different methods, such as fractal Langmuir, fractal BET, fractal Frenkel-Halsey-Hill $(\mathrm{FHH})$ and the thermodynamic method, have been proposed to calculate fractal dimension based on

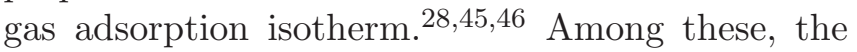
FHH model has been proved to be an effective and reliable method for several porous materials ${ }^{47-50}$ :

$$
\ln \left(V / V_{o}\right)=\text { constant }+\mathrm{K}\left[\ln \left(\ln \left(P_{o} / P\right)\right)\right]
$$

where $V$ is the volume of $\mathrm{N}_{2}$ adsorbed at the equilibrium pressure $P ; P_{0}$ is the saturation pressure; $V_{0}$ denotes the monolayer coverage volume; the constant $K$ can be obtained by the slope of the plot $\ln (V)$ versus $\ln \left(\ln \left(P_{0} / P\right)\right)$. Then, the fractal dimension $(D)$ can be calculated using the following equation: $D=K+3$. Fractal dimensions obtained from $\mathrm{FHH}$ model using nitrogen adsorption have been discussed in great detail elsewhere.29

\section{RESULTS}

\subsection{Geochemical and Mineralogical Parameters}

The mineral constituents, geochemical parameters of tested lacustrine shale samples are listed in Table 1 TOC contents range from $1.56 \%$ to $5.62 \%$, with an average value of $3.04 \%$. The thermal maturity of lacustrine shales in Ordos Basin is in mature

Table 1 Representative Sample Information.

\begin{tabular}{lcccc}
\hline $\begin{array}{l}\text { Sample } \\
\text { ID }\end{array}$ & $\begin{array}{c}\text { TOC } \\
(\%)\end{array}$ & $\begin{array}{c}\text { He } \\
\text { Porosity }\end{array}$ & $\begin{array}{c}\text { Kerogen } \\
\text { Type }\end{array}$ & $\begin{array}{c}\boldsymbol{R}_{\boldsymbol{O}} \\
(\boldsymbol{\%})\end{array}$ \\
\hline LW-C1 & 1.56 & 2.23 & III & 1.08 \\
LW-C3 & 2.31 & 2.65 & III & - \\
LW-C4 & 2.11 & 1.58 & III & 0.96 \\
LW-C8 & 5.62 & 5.01 & III & - \\
LW-C10 & 1.92 & 1.26 & III & - \\
LW-C13 & 3.63 & 2.37 & III & 1.18 \\
LW-C15 & 4.12 & 3.21 & III & 1.13 \\
\hline
\end{tabular}

Note: TOC $=$ total organic carbon, $R_{O}=$ vitrinite reflectance. 


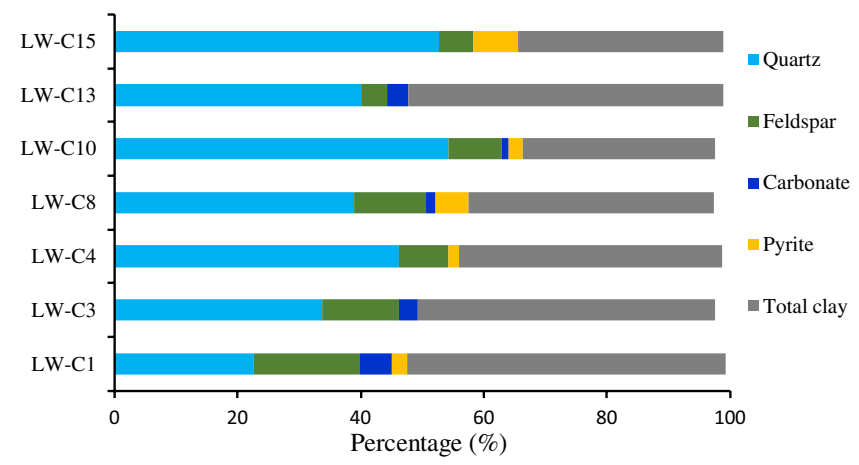

Fig. 2 Chemical composition for six Chinese marine shales.

stage, as indicated by a vitrinite reflectance $\left(R_{o}\right)$ value ranging from $0.96 \%$ to $1.18 \%$ with type III organic matter (OM). In addition, XRD analysis demonstrates that lacustrine shales have an extremely complex mineral composition (Fig. 2). Minerals are dominated by quartz and clay, with an average of $41.2 \%(22.6-54.3 \%)$ and $42.6 \%$ (31.2$51.6 \%$ ), respectively (Table 21). Lacustrine shales also contain carbonate, feldspar and pyrite, etc. Further analyses of clay demonstrate that the illite and illite-montmorillonite mixed layer are the primary clay constituents, with a mean content of $16.9 \%$ and $11.9 \%$, respectively.

In addition, helium pycnometry tests reveal that the porosity of lacustrine shales varies between $1.26 \%$ and $5.01 \%$, with an average value of $2.62 \%$. The porosity correlates positively with the TOC $\left(R^{2}=0.7856\right.$, Fig. 3 a $)$. We also found that there is no obvious relationship between porosity and clay minerals (Fig. 3b), which indicates that in this study OM plays a dominating effect on porosity. Also, the cause of this poor correlation may indicate there are other types of pores (pyrite pores and dissolution pores) that contribute to the porosity.

\subsection{Qualitative Description of Pore Morphology from FE-SEM}

Qualitative analyses of pore morphology are informative for revealing the causes of nanoscale pores and defining the microscopic pore structures. According to the descriptive pore classifications proposed by Loucks et al., 51 pores in shale can be divided into four categories: OM pores, interparticle (interP) pores, intraparticle (intraP) pores and microfractures. Through FE-SEM observations, OM pores are well developed in the lacustrine shale, and their diameter varied from several to hundreds of nanometers. It is notable that the OM pores are often forming pore networks with good connectivity. OM pores of lacustrine shale display various shapes such as bubble-like, pit, spherical to ellipsoidal, irregular polygons and honeycomb (Figs. 4a, 4b and 4r).

IntraP pores are another major contributor to porosity of lacustrine shales. This type of pore is mainly associated with pyrite framboids, clay aggregates and dissolution of certain unstable minerals. IntraP pores are mainly polygonal and bubblelike with poor connectivity. Abundant pyrite framboids are observed in lacustrine shales (Figs. 4f, 四 and $4 \mathrm{~h}$ ). Due to the incomplete cementation or dissolution, nanoscale pores between individual pyrite crystals are produced (Fig. 4f).

In contrast with OM pores and intraP pores, interP pores are usually developed between particles or crystals and are susceptible to mechanical compaction. They exist between the contact areas of $\mathrm{OM}$ and clay minerals, along the pyrite and quartz grains (Figs. $4 \mathrm{~d}$ and $4 \mathrm{e}$ ). The pore size of intraP pores varies from $100 \mathrm{~nm}$ to $800 \mathrm{~nm}$. Note that the distribution of interP pores was quite heterogeneous with poor connectivity.

Table 2 Mineralogical Composition of the Shale Samples Based on XRD Analysis.

\begin{tabular}{lccccccccc}
\hline Samples & \multicolumn{10}{c}{ Relative Percent (\%) } \\
\cline { 2 - 10 } & Quartz & Feldspar & Carbonate & Pyrite & $\begin{array}{c}\text { Total } \\
\text { Clay }\end{array}$ & Illite & Kaolinite & $\begin{array}{c}\text { Chlorite } \\
\text { Illite-Montmorillonite } \\
\text { Mixed Layer }\end{array}$ \\
\hline LW-C1 & 22.6 & 17.2 & 5.2 & 2.6 & 51.6 & 20.8 & 3.2 & 10.8 & 16.8 \\
LW-C3 & 33.7 & 12.6 & 2.9 & - & 48.3 & 15.4 & - & 7.2 & 25.7 \\
LW-C4 & 46.2 & 8.1 & - & 1.6 & 42.8 & 18.9 & 3.2 & 7.2 & 13.5 \\
LW-C8 & 38.9 & 11.7 & 1.6 & 5.3 & 39.8 & 21.2 & 2.1 & 10.5 & 7.3 \\
LW-C10 & 54.3 & 8.5 & 1.3 & 2.3 & 31.2 & 10.7 & 1.6 & 11.6 & 10.8 \\
LW-C13 & 40.1 & 4.2 & 3.4 & - & 51.2 & 17.4 & 4.7 & 18.3 & 3.1 \\
LW-C15 & 52.8 & 5.5 & - & 7.3 & 33.2 & 13.8 & 2.1 & 13.2 & \\
\hline
\end{tabular}

Note: ${ }^{\text {a Total }}$ clay $=$ illite + kaolinite + chlorite + illite-montmorillonite mixed layer. 
Y. Wang et al.

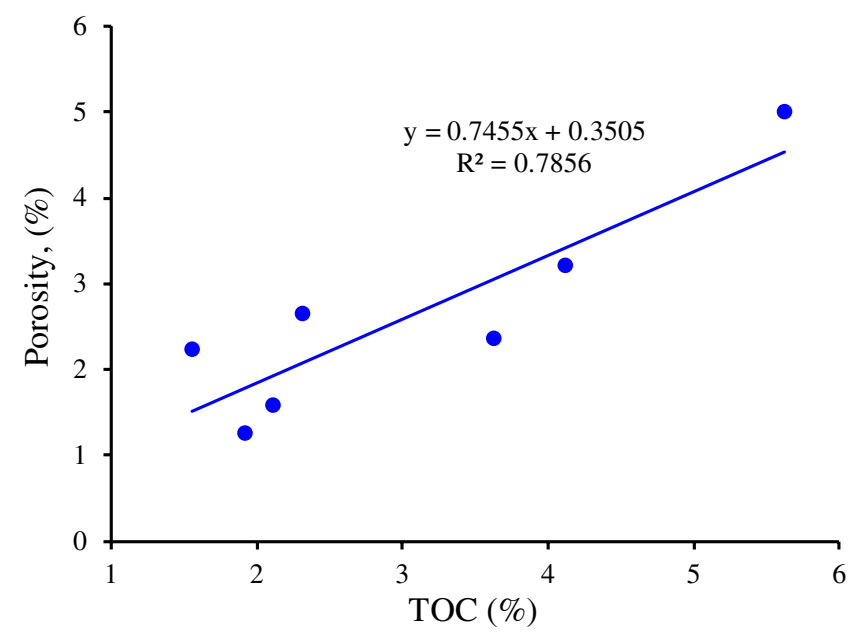

(a)

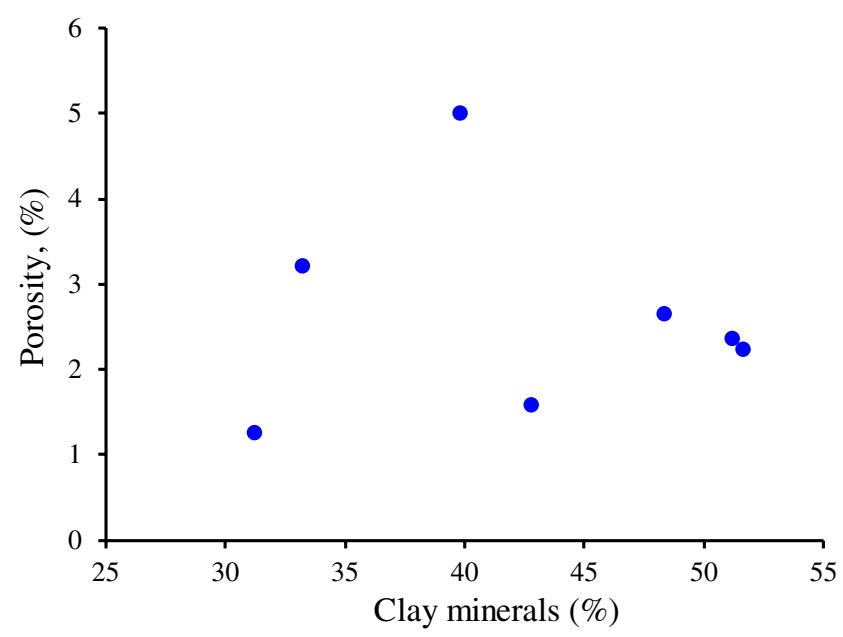

(b)

Fig. 3 Relationships between the porosity and TOC (a) and clay minerals (b).
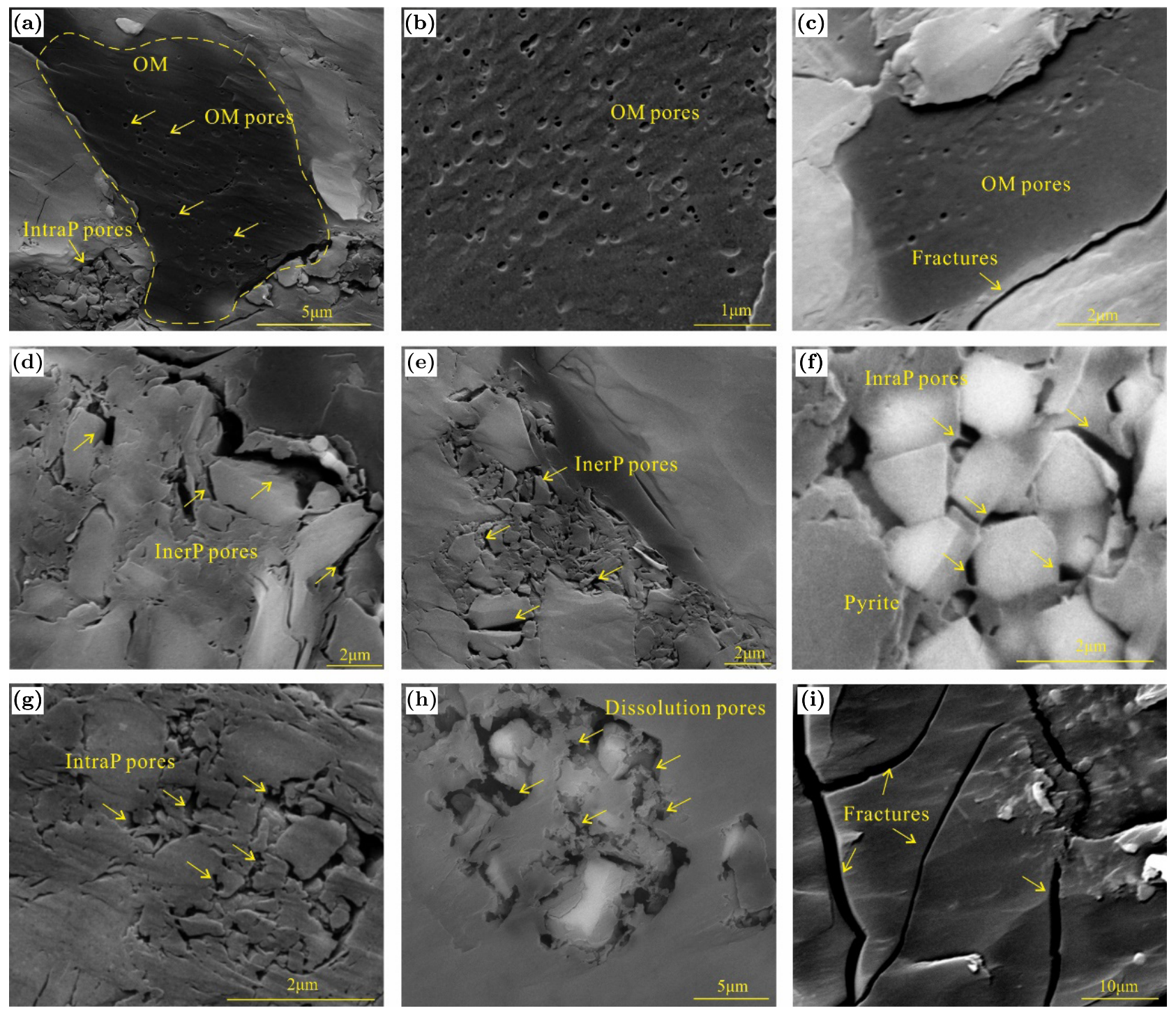

Fig. 4 FE-SEM images of the lacustrine shale showing different types of pores. 
Various kinds of microfractures are observed in lacustrine shales. Microfractures usually observed within unstable minerals result from dissolution, and are 200-800 $\mathrm{nm}$ wide and $40 \mu \mathrm{m}$ long (Fig. 4i ). Some microfractures may connect micropores and macropores which can improve the connectivity of the pore networks. Therefore, microfractures not only provide space for free and adsorbed gas, but also serve an important role in shale gas migration.

\subsection{Pore Characterization Using $\mathrm{N}_{2}$ Adsorption Isotherms}

The $\mathrm{N}_{2}$ adsorption/desorption isotherms for selected lacustrine shale samples are shown in Fig. 5. It can be noted that the adsorption-desorption process is not reversible, as observed by the presence of hysteresis loops. Considering the shape of the hysteresis loops, we suggest that the loops contain two main types (Type H2 and Type H3) according to the IUPAC classification.52 Also note that according to the de Boer classification, the hysteresis loops' shape corresponds to the type B and type $\mathrm{E}$, indicating the presence of slit-shaped pores and ink-bottle pores .535 In the type $\mathrm{H} 2$ samples (such as LW-C15), pores with narrow necks and wider bodies (ink bottles) can be observed, whereas the type H3 samples (such as LW-C4) are associated with aggregates of plate-like particles giving rise to slit-shaped pores. The slit-shaped pores may be related to the plate structure of clay particles (Fig. 4g $)$.

Low-pressure nitrogen gas adsorption analyses provided data on the BET surface area and BJH
Table 3 Representative Sample Information.

\begin{tabular}{lcccr}
\hline Sample & $\begin{array}{c}\text { TOC } \\
\text { ID }\end{array}$ & $\begin{array}{c}\mathbf{N}_{\mathbf{2}} \text { BET } \\
\text { Surface Area } \\
\left(\mathbf{m}^{2} / \mathbf{g}\right)\end{array}$ & $\begin{array}{c}\mathbf{N}_{\mathbf{2}} \text { BJH Pore } \\
\text { Volume } \\
\left(\mathbf{c m}^{\mathbf{3}} / \mathbf{1 0 0 g}\right)\end{array}$ & $\begin{array}{c}\text { Average } \\
\text { Size Pore } \\
(\mathbf{n m})\end{array}$ \\
\hline LW-C1 & 1.56 & 2.756 & 0.714 & 15.150 \\
LW-C3 & 2.31 & 5.230 & 0.521 & 10.320 \\
LW-C4 & 2.11 & 3.571 & 0.681 & 17.340 \\
LW-C8 & 5.62 & 10.26 & 1.276 & 5.622 \\
LW-C10 & 1.92 & 4.523 & 0.982 & 17.230 \\
LW-C13 & 3.63 & 6.761 & 0.692 & 8.031 \\
LW-C15 & 4.12 & 5.126 & 1.310 & 19.200 \\
\hline
\end{tabular}

pore volumes (Table 3). The BET specific surface areas of shale samples range from $2.76 \mathrm{~m}^{2} / \mathrm{g}$ to $10.26 \mathrm{~m}^{2} / \mathrm{g}$, with a mean value of $5.46 \mathrm{~m}^{2} / \mathrm{g}$. Meanwhile, the pore volume varies from $0.52 \mathrm{~m}^{3} / 100 \mathrm{~g}$ to $1.31 \mathrm{~m}^{3} / 100 \mathrm{~g}$, with a mean value of $0.88 \mathrm{~m}^{3} / 100 \mathrm{~g}$. In addition, the pore size ranges from $5.62 \mathrm{~nm}$ to $19.20 \mathrm{~nm}$. Note that sample LW-C15 contains the largest average pore size, and sample LW-C8 contains the smallest.

In addition, correlational analysis between the TOC and pore structure parameters was performed on samples from the lacustrine shale in Ordos Basin in this study. The results indicate that there is a strong correlation between the TOC and BET surface area $\left(R^{2}=0.8191\right.$; Fig. 67 $)$. Also, a moderate positive relationship was found between TOC and pore volume $\left(R^{2}=0.5027\right.$; Fig. 6b). These good relationships indicate that OM play an important role in pore system of lacustrine shale. Shale samples with higher TOC content trend to process larger surface area and pore volume, which are consistent with previous studies. $\underline{5455}$
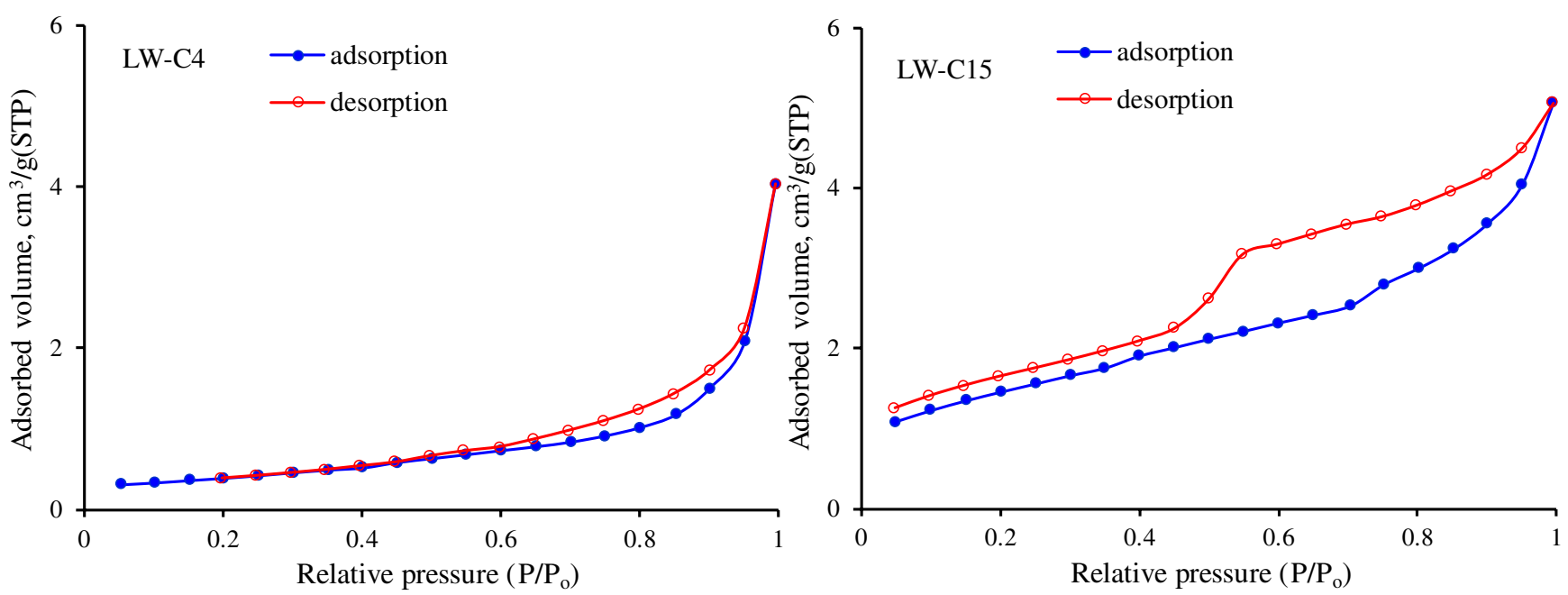

Fig. $5 \mathrm{~N}_{2}$ adsorption/desorption isotherms of representative shale samples. 
Y. Wang et al.

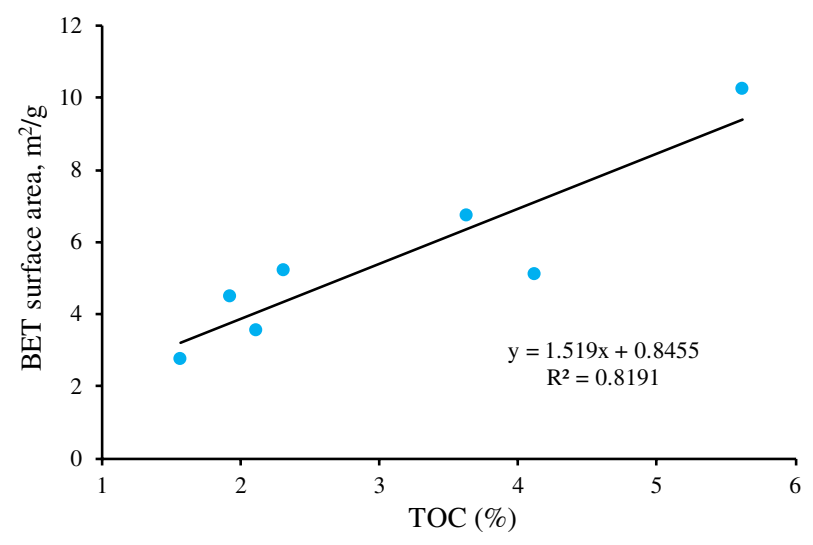

(a)

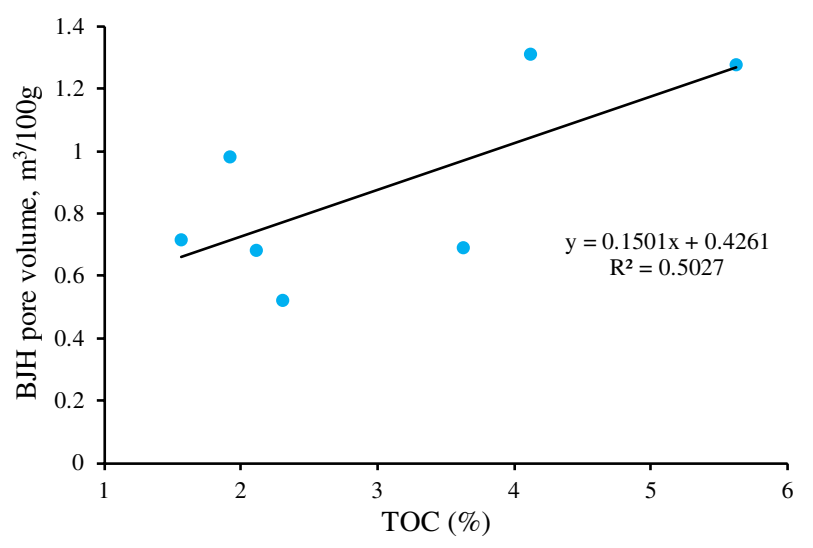

(b)

Fig. 6 Relationship between TOC and pore parameters.

\subsection{Fractal Dimensions from $\mathrm{N}_{2}$ Adsorption Isotherms}

Based on adsorption branch data of $\mathrm{N}_{2}$ adsorption isotherms dealing with FHH method, the representative $\ln (V)-\ln \left(\ln \left(P_{0} / P\right)\right)$ plots of lacustrine shales are illustrated in Fig. 7. For lacustrine shale samples, there are two distinct straight line segments at the whole relative pressure range with different slopes with good fits (Fig. 7). All correlation coefficients are higher than 0.95 . This phenomenon probably indicates different gas adsorption mechanisms in these two regions. The regressed values
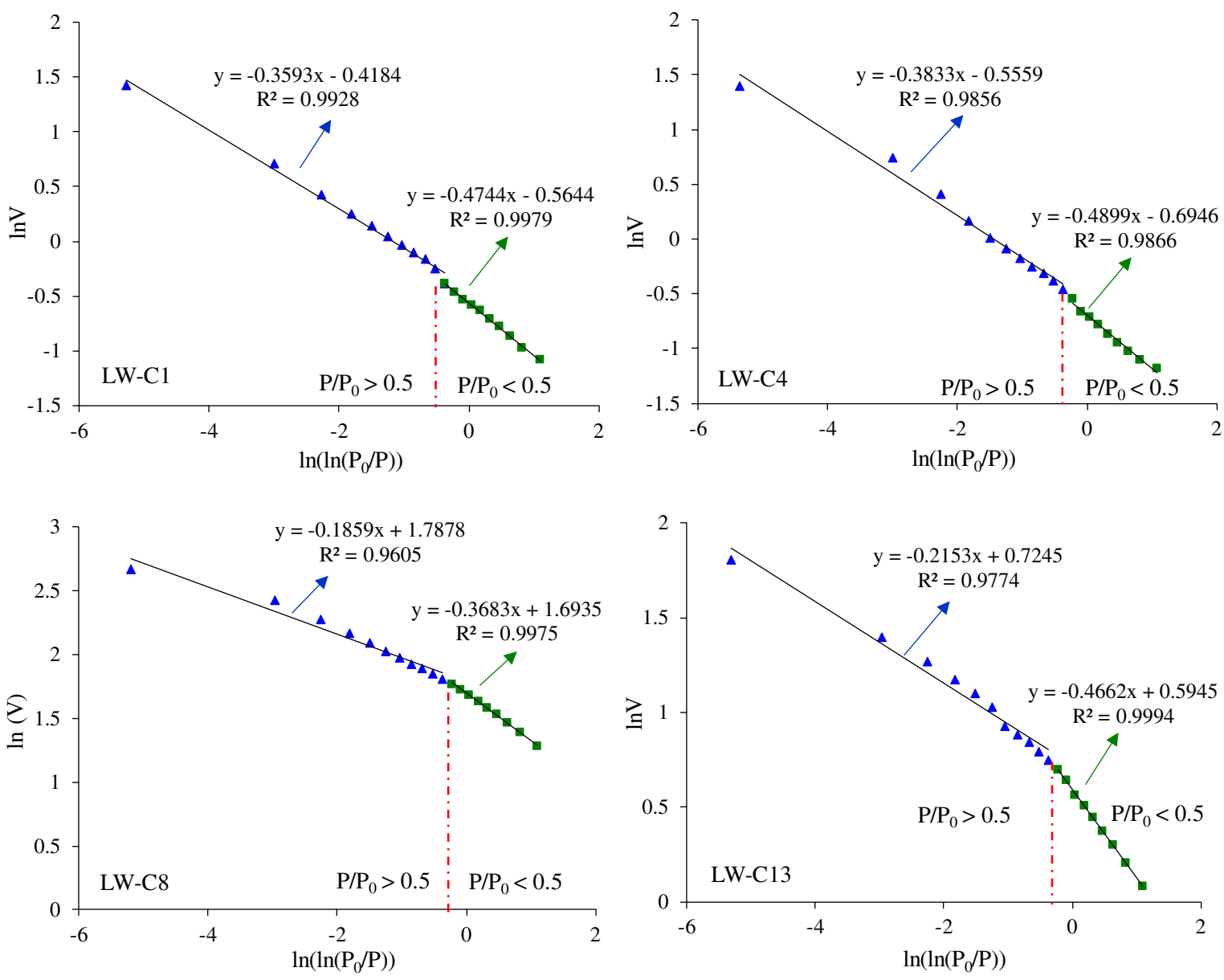

Fig. 7 Fractal dimension calculation results from $N_{2}$ adsorption isotherms. 
Table 4 Fractal Dimensions of Marine Shale Samples.

\begin{tabular}{lccccccc}
\hline Sample ID & \multicolumn{3}{c}{$\mathbf{P} / \mathbf{P}: \mathbf{0}-\mathbf{0 . 5}$} & & \multicolumn{3}{c}{ P/P: 0.5 - 1 } \\
\cline { 2 - 3 } & $\boldsymbol{K}_{\mathbf{1}}$ & $\boldsymbol{D}_{\mathbf{1}}=\mathbf{3}+\boldsymbol{K}_{\mathbf{1}}$ & $\boldsymbol{R}_{\mathbf{1}}^{\mathbf{2}}$ & & $\boldsymbol{K}_{\mathbf{2}}$ & $\boldsymbol{D}_{\mathbf{2}}=3+\boldsymbol{K}_{\mathbf{2}}$ & $\boldsymbol{R}_{\mathbf{2}}^{\mathbf{2}}$ \\
\hline LW-C1 & -0.474 & 2.526 & 0.998 & & -0.359 & 2.641 & 0.993 \\
LW-C3 & -0.430 & 2.570 & 0.960 & -0.239 & 2.761 & 0.997 \\
LW-C4 & -0.490 & 2.510 & 0.987 & -0.383 & 2.617 & 0.986 \\
LW-C8 & -0.368 & 2.632 & 0.998 & -0.186 & 2.814 & 0.961 \\
LW-C10 & -0.474 & 2.526 & 0.999 & -0.380 & 2.620 & 0.996 \\
LW-C13 & -0.466 & 2.534 & 0.999 & -0.215 & 2.785 & 0.977 \\
LW-C15 & -0.458 & 2.542 & 0.999 & -0.327 & 2.673 & 0.957 \\
\hline
\end{tabular}

of slopes, $K_{1}$ and $K_{2}$, and the calculated fractal dimension values, $D_{1}$ and $D_{2}$ are listed in Table 4 . The fractal dimension $D_{1}$ ranges from 2.510 to 2.632 , with an average value of 2.549 . The fractal dimension $D_{2}$ ranges from 2.617 to 2.814 , with an average value of 2.702 , which is larger than $D_{1}$.

\section{DISCUSSION}

\subsection{Pore Characterization of Various Types of Pores from FE-SEM}

In this study, in order to quantitatively assess the pore structure of different types of pores, ImagePro Plus software was used to extract various pores from FE-SEM images of each sample. Our process involved identifying pores in the image, preliminarily choosing an appropriate threshold value, and then adjusting the threshold value until we observed the best effect. A total of eleven FE-SEM images of lacustrine shales were imported into the ImagePro Plus software (Fig. 8). OM pores, InterP pores and IntraP pores were segmented, and the average pore size, surface porosity and fractal dimension were recorded. To reduce possible errors, FE-SEM
Table 5 Pore Structures Obtained by Image-Pro Plus Software.

\begin{tabular}{lcccc}
\hline $\begin{array}{l}\text { Pore } \\
\text { Type }\end{array}$ & $\begin{array}{c}\text { Number } \\
\text { Pores }\end{array}$ & $\begin{array}{c}\text { Average } \\
\text { Pore Size } \\
(\mathbf{n m})\end{array}$ & $\begin{array}{c}\text { Surface } \\
\text { Porosity } \\
(\mathbf{( \% )}\end{array}$ & $\begin{array}{c}\text { Fractal } \\
\text { Dimension } \\
\left(\mathbf{D}_{\mathbf{M}}\right)\end{array}$ \\
\hline OM pores & 521 & 36.6 & $1.52 \%$ & 1.09 \\
InterP pore & 313 & 165.2 & $8.12 \%$ & 1.34 \\
IntraP pore & 286 & 236.6 & $9.53 \%$ & 1.27 \\
\hline
\end{tabular}

images of lacustrine shales with clear pore boundaries were used, and appropriate threshold filters of hue, brightness and saturation were adjusted to distinguish pores from the matrix.

Values of the pore structure parameters are listed in Table 5. There are substantial differences between the three pore types. OM pores are the smallest pores observed and the average pore size is $36.6 \mathrm{~nm}$. InterP pores and intraP pores are much larger than OM pores, with average pore size of 165.2 and 236.6, respectively. Meanwhile, the surface porosity of different pores was chosen as one of the quantitative parameters to characterize pore structure. The surface porosity of pores is the area fraction of the pores across certain zones. The average surface porosity of OM pores was $1.52 \%$.
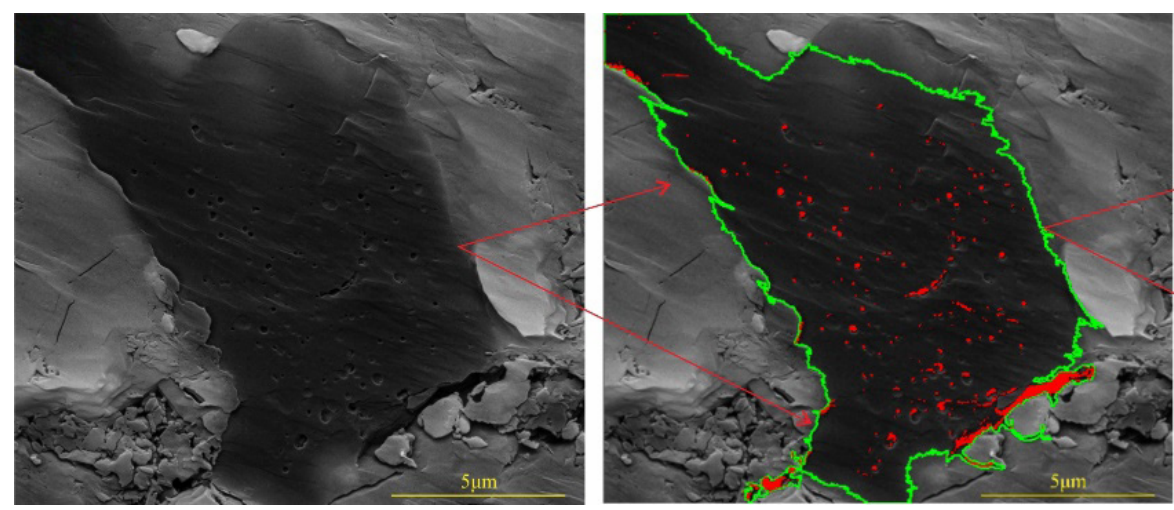

(a)

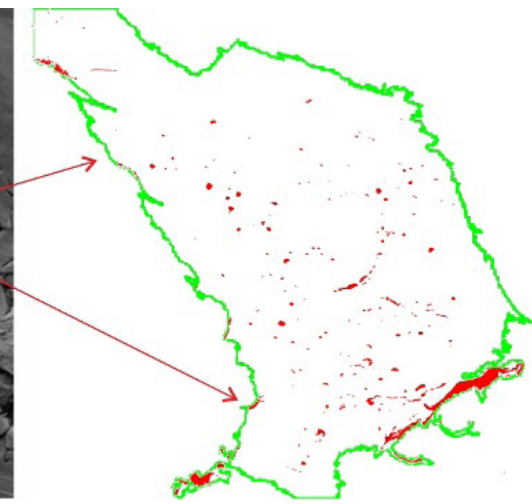

Fig. 8 Original FE-SEM images of representative shale samples and each image processed using Image-Pro Plus software. 

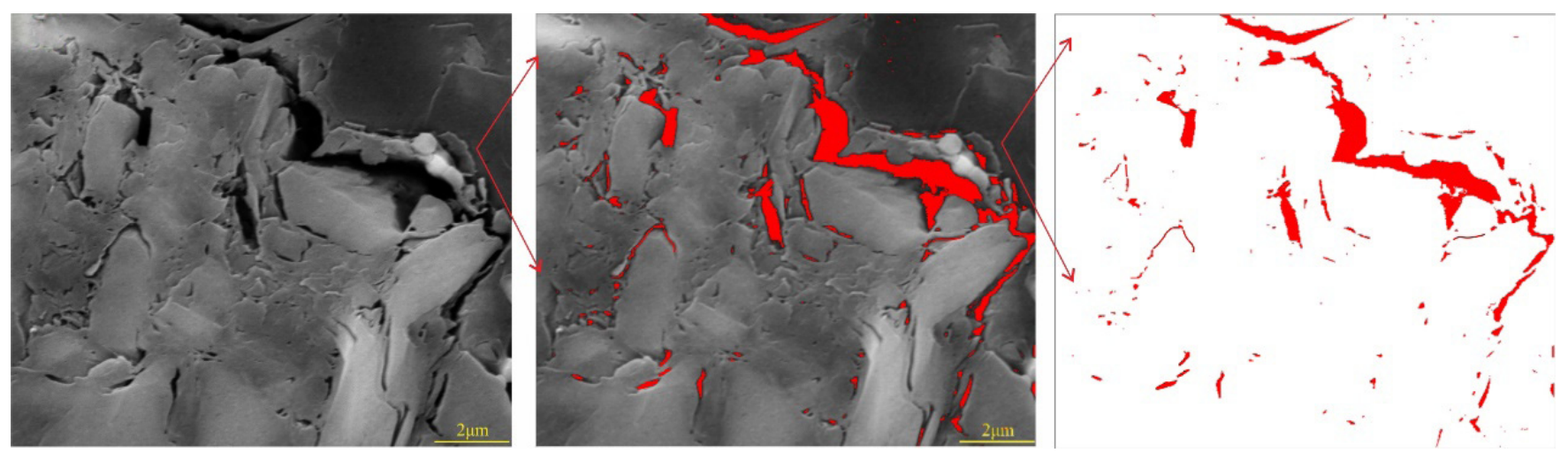

(b)
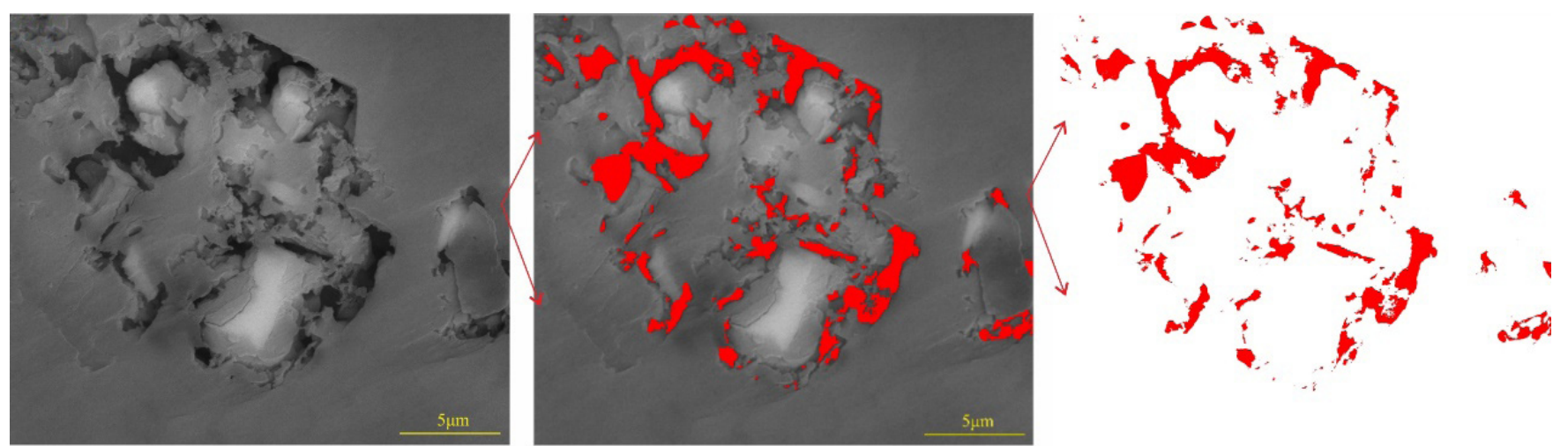

(c)

Fig. 8 (Continued)

IntraP pores offer the largest surface porosity, with an average of $9.53 \%$.

To better characterize pore morphology in the present study, fractal dimension obtained from high-resolution FE-SEM images has been used. The Mandelbrot dimension $\left(D_{M}\right)$ mainly reflects the irregularity of pore margins. $\frac{5758}{5}$ If a pore system can be described in fractal terms, then mandelbrot fractal geometry can be described as follows 59 .

$$
\log (P)=D_{M} / 2 \cdot \log (S)+c_{1},
$$

where $P$ is the pore perimeter, $S$ is the pore area and $c_{1}$ is a constant. The $D_{M}$ can be obtained from the absolute value of the slope coefficient of the linear regression of $\log (P)$ against $\log (S)$. For a twodimensional image, the value of the $D_{M}$ is between 1 and 2.

Since fractal dimension $\left(D_{M}\right)$ is useful indicator of pore shape, it is worth noting that the OM pores have lowest shape complexity and the average fractal dimension is $1.09 \%$. InterP pores and intraP pores commonly have a pore shape with higher complexity because of the higher fractal dimension. This is generally consistent with previous research 60

\subsection{Relationships Between Fractal Dimensions and TOC Content and Mineral Composition}

Based on different adsorption characteristic at different pressure range, Yao et al. $\stackrel{28}{\text { suggested that }}$

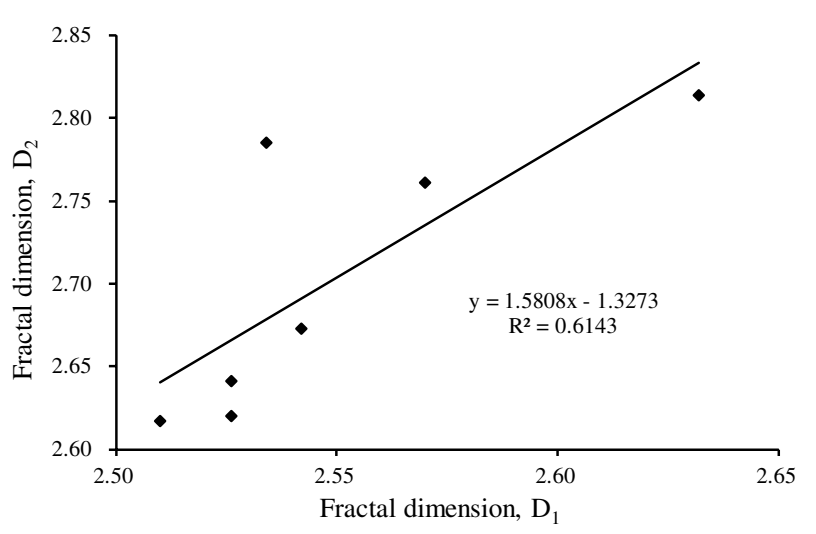

Fig. 9 Relationship between the fractal $D_{1}$ and $D_{2}$ of lacustrine shale. 


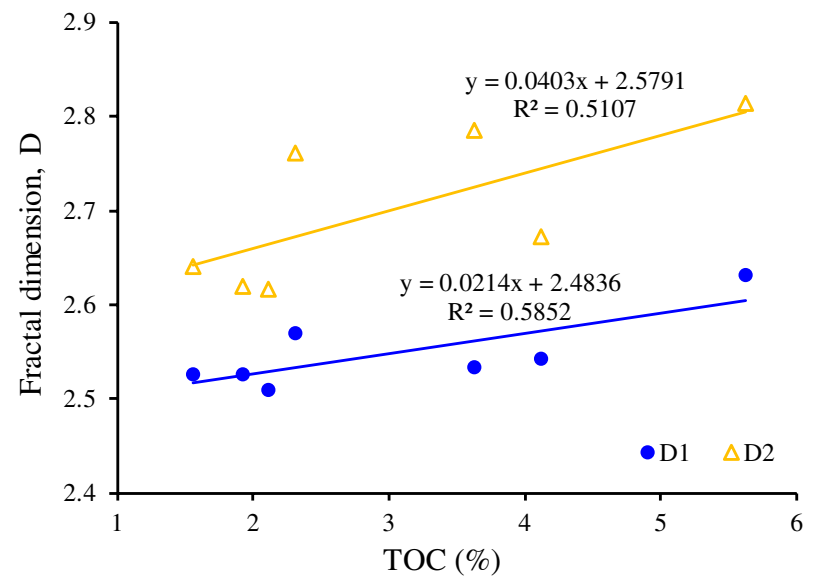

(a)

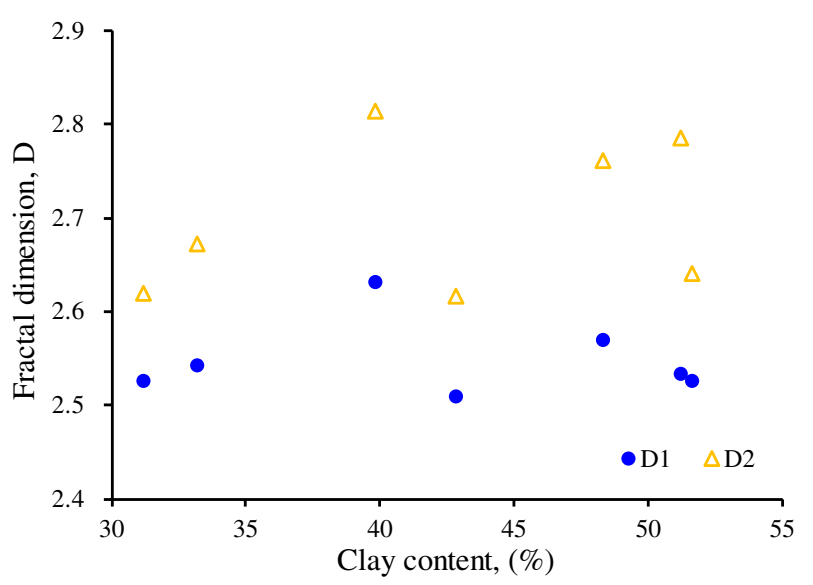

(b)

Fig. 10 Relationships between TOC content, clay content and fractal dimensions of lacustrine shale.

the fractal dimension $D_{1}$ in the region of $P / P_{0}<0.5$ characterizes the action of Van der Waals forces and reflects the surface roughness. However, the fractal dimension $D_{2}$ was obtained in the region of $P / P_{0}>0.5$, and the monolayer adsorption developed into multilayer adsorption. Therefore, $D_{2}$ can describe the space roughness of the lacustrine pore structure and can be used to define the pore structure irregularity. Unlike the discrepancies in $D_{1}$ and $D_{2}$ of coals, $\stackrel{28}{2}$ there is a positive correlation between $D_{1}$ and $D_{2}$ of lacustrine shale (Fig. 9), indicating that fractal dimensions $D_{1}$ and $D_{2}$ have an internal connection with each other.

When the TOC content was plotted against the two fractal dimensions for the lacustrine shales, it was found that TOC content positively correlates with fractal dimensions $D_{1}$ and $D_{2}$ as shown in Fig. 10 . Shale samples with higher TOC content have greater fractal dimensions. This phenomenon probably indicate that the number of micropores increased with the increasing TOC content, which lead to more complicated pore structure. However, no definite relationship was observed between fractal dimensions and clay minerals as shown in Fig. 10p. This may be caused by the complex pore systems developed in clay minerals. Also, compared to $\mathrm{OM}$ pores, clay mineral intergranular pores are more sensitive to compaction and diagenesis, which partly explains why clay minerals have little effect on fractal dimensions.

\subsection{Relationships Between Fractal Dimensions and Pore Structure Parameters}

The correlation between fractal dimensions and BET surface area and BJH pore volume are illustrated in Figs. 117 and 11b. Positive relationships

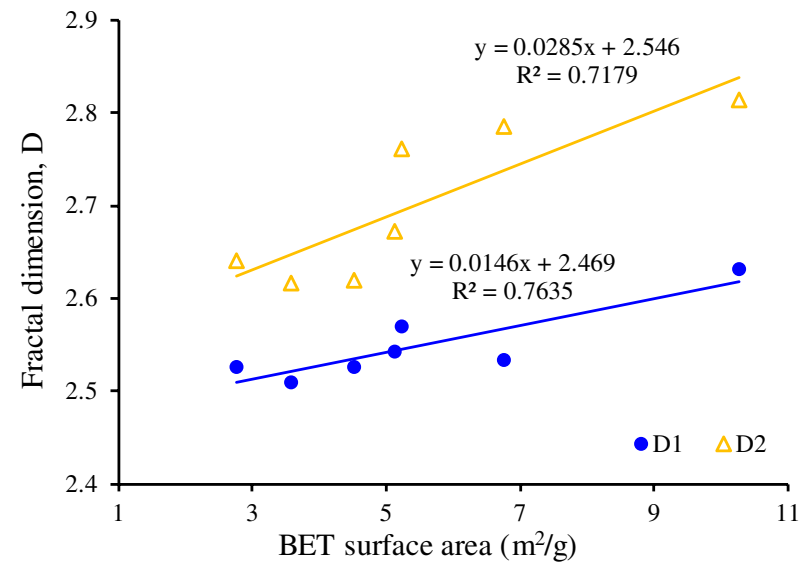

(a)

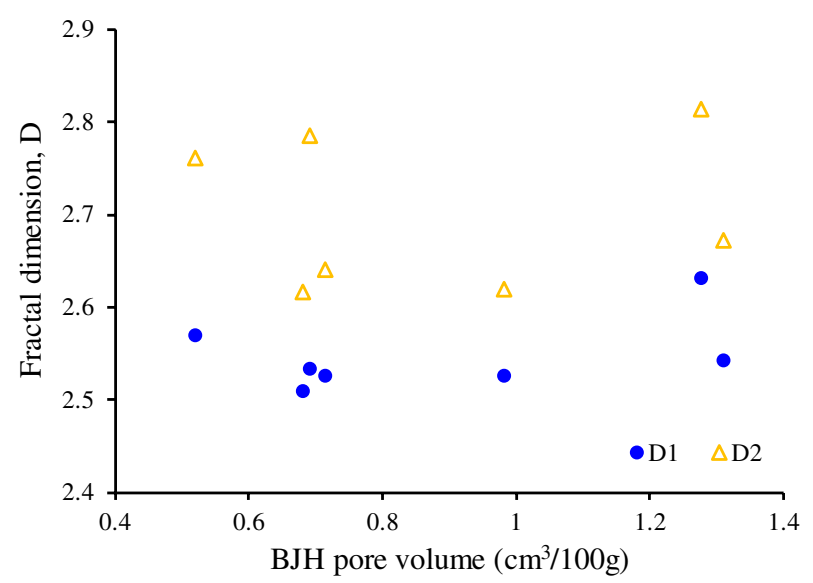

(b)

Fig. 11 Relationships between pore structures and fractal dimensions of lacustrine shale. 


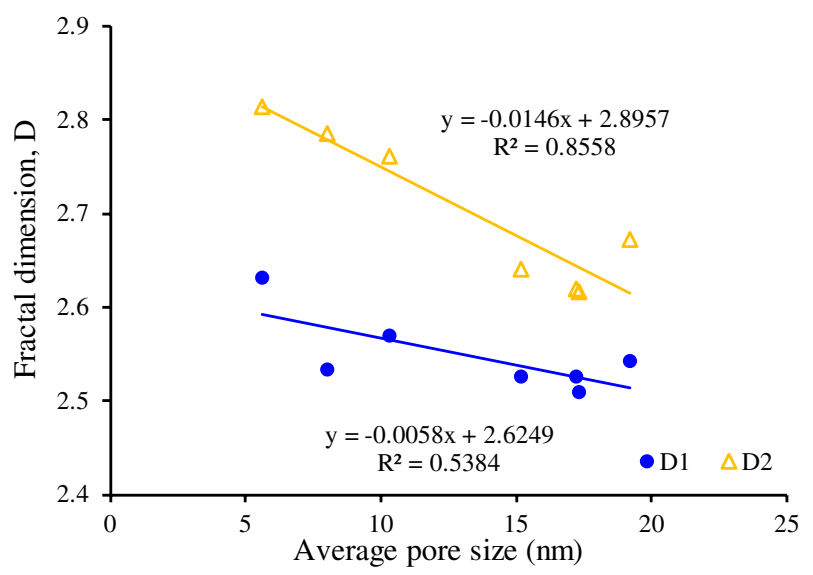

(c)

Fig. 11 (Continued)

obviously exist between the fractal dimensions and BET surface area. Thus, these positive relationships indicate that lacustrine shales with higher value of fractal dimensions tend to have rougher internal surfaces at which more active adsorption sites were available for methane. Meanwhile, the relationships between fractal dimensions and BJH pore volumes are not apparent, indicating that pore volumes have little effect on fractal dimensions. One possible reason might be that pore volumes are mainly contributed by mesopores, macropores and microfractures. Nevertheless, fractal dimensions are mainly associated with the complexity of micropores in the shale.

Furthermore, the average pore size of lacustrine shale shows a significant negative relationship with fractal dimension $D_{2}$, with a correlation coefficient of 0.8558 , and a moderate negative relationship was also observed between the average pore size and fractal dimension $D_{1}\left(R^{2}=0.5384\right)$, indicating that fractal dimensions decrease rapidly with the increase of pore size. These negative relationships are consistent with previous studies, implying that lacustrine shales with smaller average pore size tend to have a more complex pore structure.

\section{CONCLUSIONS}

In this study, we combined FE-SEM, He porosimetry, Low-pressure $\mathrm{N}_{2}$ adsorption techniques and fractal theory to investigate the fractal characterization of multiscale pore structures of lacustrine shales. Based on the results, the following conclusions have been made:
(1) The FE-SEM images show that OM pores are the most important type dominating the pore system of the lacustrine shales.

(2) Based on the $\mathrm{N}_{2}$ adsorption isotherms, fractal dimensions were calculated by the $\mathrm{FHH}$ method. Two different fractal dimensions, $D_{1}$ and $D_{2}$, were obtained, with $D_{1}$ varying between 2.510 and 2.632, and $D_{2}$ varying between 2.617 and 2.814 .

(3) Based on the FE-SEM images, various types of pores were identified and analyzed by Image-Pro Plus software. The shapes of OM pores are less complex compared with the other two pore types.

(4) OM has an enormous effect on fractal dimensions. Lacustrine shales with higher TOC have a greater fractal dimension, indicating more irregular surface and higher heterogeneity of pore structures.

(5) The fractal dimensions of lacustrine shale samples increase with increasing BET surface area, implying that higher fractal dimensions can provide more adsorption sites for methane. The fractal dimensions are negatively correlated with the pore size.

\section{ACKNOWLEDGMENTS}

The authors would like to thank the financial support of the National Natural Science Foundation of China (No. 41572140) and the Fundamental Research Funds for the Central Universities (No. 2017CXNL03), National Science and Technology Major Project (2016ZX05044-001 and 2017ZX05035004-002), the National Postdoctoral Program for Innovative Talents (BX201700282) 
and the China Postdoctoral Science Foundation (2017M621870).

\section{REFERENCES}

1. F. Xiong et al., The shale gas sorption capacity of transitional shales in the Ordos Basin, NW China, Fuel 208 (2017) 236-246.

2. C. N. Zou et al., Shale gas in China: Characteristics, challenges and prospects (I), Pet. Explor. Dev. 42(6) (2015) 753-767.

3. W. Z. Zhao et al., Geological difference and its significance of marine shale gases in South China, Pet. Explor. Dev. 43(4) (2016) 547-559.

4. C. R. Clarkson et al., Pore structure characterization of North American shale gas reservoirs using USANS/SANS, gas adsorption and mercury intrusion, Fuel 103 (2013) 606-616.

5. G. R. L. Chalmers, R. M. Bustin and I. M. Power, Characterization of gas shale pore systems by porosimetry, pycnometry, surface area and field emission scanning electron microscopy/transmission electron microscopy image analyses: Examples from the Barnett, Woodford, Haynesville, Marcellus and Doig units, AAPG Bull. 96(6) (2012) 1099-1119.

6. R. G. Loucks et al., Spectrum of pore types and networks in mudrocks and a descriptive classification for matrix-related mudrock pores, AAPG Bull. 96 (2012) 1071-1098.

7. M. Sun et al., Pore characteristics of Longmaxi shale gas reservoir in the Northwest of Guizhou, China: Investigations using small-angle neutron scattering (SANS), helium pycnometry, and gas sorption isotherm, Int. J. Coal Geol. 171 (2017) 61-68.

8. J. Rouquerol et al., Recommendations for the characterization of porous solids (Technical Report), Pure Appl. Chem. 66(8) (1994) 1739-1758.

9. A. Furmann et al., Relationships between porosity, organic matter, and mineral matter in mature organic-rich marine mudstones of the Belle Fourche and Second White Specks formations in Alberta, Canada, Mar. Pet. Geol. 54 (2014) 65-81.

10. F. Hao, H. Zou and Y. Lu, Mechanisms of shale gas storage: Implications for shale gas exploration in China, AAPG Bull. 97(8) (2013) 1325-1346.

11. M. Mastalerz et al., Porosity of Devonian and Mississippian New Albany Shale across a maturation gradient: Insights from organic petrology, gas adsorption, and mercury intrusion, AAPG Bull. 97 (2013) 1621-1643.

12. K. L. Milliken et al., Organic matter-hosted pore system, Marcellus formation (Devonian), Pennsylvania, AAPG Bull. 97 (2013) 177-200.

13. D. J. K. Ross and R. M. Bustin, The importance of shale composition and pore structure upon gas storage potential of shale gas reservoirs, Mar. Pet. Geol. 26(6) (2009) 916-927.

14. J. Tuo, C. Wu and M. Zhang, Organic matter properties and shale gas potential of Paleozoic shales in Sichuan Basin, China, J. Nat. Gas Sci. Eng. 28 (2016) 434-446.

15. H. Tian et al., Pore characterization of organicrich lower Cambrian shales in Qiannan depression of Guizhou province, Southwestern China, Mar. Pet. Geol. 62 (2015) 28-43.

16. Y. Wang et al., Nanoscale pore morphology and distribution of lacustrine shale reservoirs: Examples from the Upper Triassic Yanchang Formation, Ordos Basin, J. Energ. Chem. 24(4) (2015) 512-519.

17. J. Zhang et al., Quantitative characterization of pore-fracture system of organic-rich marinecontinental shale reservoirs: A case study of the Upper Permian Longtan Formation, Southern Sichuan Basin, China, Fuel 200 (2017) 272-281.

18. R. Yang et al., Applying SANS technique to characterize nano-scale pore structure of Longmaxi shale, Sichuan Basin (China), Fuel 197 (2017) 91-99.

19. Y. Chen, M. Mastalerz and A. Schimmelmann, Heterogeneity of shale documented by microFTIR and image analysis, J. Microsc. 256(3) (2014) 177-189.

20. Y. Wang et al., Pore characterization and its impact on methane adsorption capacity for organic-rich marine shales, Fuel 181 (2016) 227-237.

21. J. Bahadur et al., Small-angle and ultrasmall-angle neutron scattering (SANS/USANS) study of New Albany shale: A treatise on microporosity, Energy Fuels 29(2) (2015) 567-576.

22. L. Chen et al., Quantitative characterization of micropore structure for organic-rich Lower Silurian shale in the Upper Yangtze Platform, South China: Implications for shale gas adsorption capacity, $A d v$. Geo-Energ. Res. 1(2) (2017) 112-123.

23. X. Shao et al., Pore structure and fractal characteristics of organic-rich shales: A case study of the lower Silurian Longmaxi shales in the Sichuan Basin, SW China, Mar. Pet. Geol. 80 (2017) 192-202.

24. H. Bu et al., Fractal characteristics of pores in nonmarine shales from the Huainan coalfield, eastern China, J. Nat. Gas Sci. Eng. 24 (2015) 166-177.

25. T. Cao et al., Characterization of pore structure and fractal dimension of Paleozoic shales from the northeastern Sichuan Basin, China, J. Nat. Gas Sci. Eng. 35 (2016) 882-895.

26. J. Z. Liu et al., Pore structure and fractal analysis of Ximeng lignite under microwave irradiation, Fuel 146 (2015) 41-50.

27. J. Medek and Z. Weishauptova, The microporous phase of carbonaceous substances and its fractal dimension, Fuel 79(13) (2000) 1621-1626.

28. Y. Yao et al., Fractal characterization of adsorptionpores of coals from North China: An investigation on 
$\mathrm{CH}_{4}$ adsorption capacity of coals, Int. J. Coal Geol. 73(1) (2008) 27-42.

29. S. Zhang et al., Determining fractal dimensions of coal pores by FHH model: Problems and effects, $J$. Nat. Gas Sci. Eng. 21 (2014) 929-939.

30. S. Blacher et al., On the texture characterization of mixed $\mathrm{SiO} 2-\mathrm{ZrO} 2$ aerogels using the nitrogen adsorption-desorption isotherms: Classical and fractal methods, Langmuir 13(5) (1997) 1145-1149.

31. L. Chen et al., Effect of lithofacies on gas storage capacity of marine and continental shales in the Sichuan Basin, China, J. Nat. Gas Sci. Eng. 36 (2016) 773-785.

32. J. Hu, S. Tang and S. Zhang, Investigation of pore structure and fractal characteristics of the Lower Silurian Longmaxi shales in western Hunan and Hubei Provinces in China, J. Nat. Gas. Sci. Eng. 28 (2016) $522-535$.

33. L. H. Zhang et al., Fractal pore structure model and multilayer fractal adsorption in shale, Fractals $\mathbf{2 2}(3)$ (2014) 10-102.

34. A. Sakhaee-Pour and W. Li, Fractal dimensions of shale, J. Nat. Gas Sci. Eng. 30 (2016) 578-582.

35. P. Wang et al., Heterogeneity of intergranular, intraparticle and organic pores in Longmaxi shale in Sichuan Basin, South China: Evidence from SEM digital images and fractal and multifractal geometries, Mar. Pet. Geol. 72 (2016) 122-138.

36. W. Ji et al., Fractal characteristics of nano-pores in the Lower Silurian Longmaxi shales from the Upper Yangtze Platform, south China, Mar. Pet. Geol. 78 (2016) 88-98.

37. X. Liu, J. Xiong and L. Liang, Investigation of pore structure and fractal characteristics of organic-rich Yanchang formation shale in central China by nitrogen adsorption/desorption analysis, J. Nat. Gas Sci. Eng. 22 (2015) 62-72.

38. M. Wang et al., Fractal characteristics of Upper Cretaceous lacustrine shale from the Songliao Basin, NE China, Mar. Pet. Geol. 67 (2015) 144-153.

39. C. N. Zou et al., Geological characteristics, formation mechanism and resource potential of shale gas in China, Petrol. Explor. Dev. 37 (2010) 641-653.

40. X. Tang et al., Shale characteristics in the southeastern Ordos Basin, China: Implications for hydrocarbon accumulation conditions and the potential of continental shales, Int. J. Coal Geol. 128 (2014) $32-46$.

41. S. J. Gregg and K. S. W. Sing, Adsorption, Surface Area and Porosity (Academic Press, London, 1982).

42. I. M. K. Ismail and P. Pfeifer, Fractal analysis and surface roughness of nonporous carbon fibers and carbon blacks, Langmuir 10(5) (1994) 1532-1538.

43. M. M. Mahamud and M. F. Novo, The use of fractal analysis in the textural characterization of coals, Fuel 87 (2008) 222-231.
44. M. R. Othman, Z. Helwani and Martunus, Simulated fractal permeability for porous membranes, Appl. Math. Model. 34(9) (2010) 2452-2464.

45. D. Avnir and M. Jaroniec, An isotherm equation for adsorption on fractal surfaces of heterogeneous porous materials, Langmuir 5(6) (1989) 1431-1433.

46. T. C. Vaimakis, C. S. Skordilis and P. J. Pomonis, Alternation of geometrical and fractal dimensions of phosphate ore particles during grinding, J. Colloid. Interfcae Sci. 172 (1995) 311-316.

47. G. J. Lee, S. I. Pyun and C. K. Rhee, Characterisation of geometric and structural properties of pore surfaces of reactivated microporous carbons based upon image analysis and gas adsorption, Microporous Mesoporous Mater. 93(1) (2006) 217-225.

48. S. P. Rigby, Predicting surface diffusivities of molecules from equilibrium adsorption isotherms, Colloids Surf. A Physicochem. Eng. Aspects 262(1) (2005) 139-149.

49. S. Q. Xu et al., Effects of pyrolysis on the pore structure of four Chinese coals, Energy Fuels 24 (2010) 1114-1123.

50. F. Yang, Z. Ning and H. Liu, Fractal characteristics of shales from a shale gas reservoir in the Sichuan Basin, China, Fuel 115 (2014) 378-384.

51. R. G. Loucks et al., Spectrum of pore types and networks in mudrocks and a descriptive classification for matrix-related mudrock pores, AAPG Bull. 96(6) (2012) 1071-1098.

52. K. S. W. Sing, Reporting physisorption data for gas/solid systems with special reference to the determination of surface area and porosity (Recommendations 1984), Pure Appl. Chem. 57(4) (1985) 603619.

53. J. H. De Boer, The shapes of capillaries, in The Structure and Properties of Porous Materials, eds. D. H. Everett and F.S. Stone (Butterworths, London, 1958), pp. 68-94.

54. G. R. L. Chalmers and R. M. Bustin, Lower cretaceous gas shales in northeastern British Columbia, part I: Geological controls on methane sorption capacity, B. Can. Pet. Geol. 56 (2008) 1-21.

55. U. Kuila et al., Nano-scale texture and porosity of organic matter and clay minerals in organic-rich mudrocks, Fuel 135 (2014) 359-373.

56. A. Dathe et al., The surface fractal dimension of the soil-pore interface as measured by image analysis, Geoderma 103(1) (2001) 203-229.

57. B .B. Mandelbrot, The Fractal Geometry of Nature (W. H. Freeman, 1983), p. 36-68.

58. R. Lopes and N. Betrouni, Fractal and multifractal analysis: A review, Med. Imag. Anal. 13(4) (2009) 634-649.

59. C. Liu et al., Quantification and characterization of microporosity by image processing, geometric measurement and statistical methods: Application on 
SEM images of clay materials, Appl. Clay Sci. 54(1) (2011) 97-106.

60. K. Jiao et al., The characterization and quantitative analysis of nanopores in unconventional gas reservoirs utilizing FESEM-FIB and image processing: An example from the lower Silurian Longmaxi Shale, upper Yangtze region, China, Int. J. Coal Geol. 128 (2014) 1-11.

61. L. Liang, J. Xiong and X. Liu, An investigation of the fractal characteristics of the Upper Ordovician
Wufeng Formation shale using nitrogen adsorption analysis, J. Nat. Gas Sci. Eng. 27 (2015) 402-409.

62. R. Yang et al., Nano-scale pore structure and fractal dimension of organic-rich Wufeng-Longmaxi shale from Jiaoshiba area, Sichuan Basin: Investigations using FE-SEM, gas adsorption and helium pycnometry, Mar. Pet. Geol. 70 (2016) 27-45. 